\title{
Replacement of Artemia spp. with zooplankton in Penaeus vannamei larviculture
}

\author{
Patricio E. Paz ${ }^{1}$, Alberto J. López-Cabús ${ }^{1}$, Lino X. Cárdenas-Nieto ${ }^{2}$ \& Wolfgang Pejuán ${ }^{2}$ \\ ${ }^{1}$ Departamento de Ciencia y Producción Agropecuaria, Escuela Agrícola Panamericana \\ Universidad Zamorano, Francisco Morazán, Honduras \\ ${ }^{2}$ Departamento de Agronegocios, Universidad Zamorano, Francisco Morazán, Honduras \\ Corresponding author: Patricio E. Paz (ppaz@zamorano.edu)
}

\begin{abstract}
Supplying healthy and cost-effective postlarvae is critical to the success of the shrimp industry. Given the cost of Artemia in larvae culture, there is considerable interest in using alternative live feeds such as copepods. This study's objective was to evaluate five diets with different proportions of Artemia and copepods offered to Penaeus vannamei larvae. Biological factors such as growth, survival to postlarvae, and final weights were evaluated in conjunction with economic factors. The diets offered were: 1) 100\% Artemia 2) $75 \%$ Artemia and 25\% copepods 3) $50 \%$ Artemia and 50\% copepods 4) $25 \%$ Artemia and $75 \%$ copepods and 5) $100 \%$ copepods. Concerning the biological response, there were no significant differences observed between the five treatments. The economic evaluation was based on a partial budget. It was concluded that there were no significant differences in survival or yields. However, the data collected in this experiment concluded that the treatment with $100 \%$ Artemia had higher annual net benefits due to the combined effect of survival rates and cost. These net benefits can vary in other repetitions, so it is recommended to experiment more times to observe differences in profits among diets.
\end{abstract}

Keywords: Artemia; Penaeus vannamei; copepods; larvae; partial budget; survival rate; aquaculture

High feed costs in the shrimp sector (larviculture) represent the main factors influencing the competitiveness and productivity of shrimp (Marroquín et al., 2012). Since the 1930s (Sorgeloos et al., 2017), larviculture has relied on Artemia spp. as a primary food source. Sanchez (2001) reported that import prices of Artemia from the USA ranged from USD 35 to 45 per $\mathrm{kg}$ in 2000, with current prices rising to around USD 100 per $\mathrm{kg}$, leading producers to seek alternative larval feeding strategies to reduce production costs (Støttrup \& Norsker, 1997; Tahim et al., 2014).

Finding a more affordable substitute that does not alter the final quality of postlarvae is necessary to maintain competitiveness, especially in crustaceans where diet quality affects their nutrient composition (D'Abramo \& Sheen, 1993; Brett \& Müller-Navarra, 1997). The alternatives for diets offered should take into consideration both nutritional and economic factor (Stoner \& Zimmerman, 1988). These factors should not cause a significant change in the survival, development of the larvae' digestive system, and resistance to a stress test (Martín et al., 2006). Shrimp producers continue to use Artemia independent of cost due to its effectiveness (Puello et al., 2008).

Publications about replacement diets in shrimp farming have not focused on economic analysis and do not show the specific costs incurred in each diet and the benefits it generates (Støttrup \& Norsker, 1997). This information would be useful for producers currently established in the market and investors interested in entering the larviculture industry, considering the costbenefit of each of the diets provided to determine the best decisions (Martínez-Córdova et al., 2010).

This project aims to find a replacement in diets of shrimp larvae culture that is more profitable than Artemia spp. The overall objective of the study was to evaluate the biological and economic value of Artemia spp. replacement strategies using copepods in larviculture of Pacific white shrimp (Penaeus vannamei). The specific objectives of the study were to determine the performance of shrimp nauplii larvae according to the diet offered, characterize the annual cycle for each applied larval diet, determine costs that vary between each of the diets, determine the net bene fits of using

Corresponding editor: Fernando Vega 
different diets offered, and analyze the marginal rate return and residual value analysis to choose the optimal diet.

The experiment was conducted at Larvicultura del Pacífico S.A. (LARVIPAC), located in Honduras. The average temperature is $28^{\circ} \mathrm{C}$, and the laboratory is located at $44 \mathrm{~m}$ above sea level. The experiment was done in $20-25 \mathrm{~m}^{3}$ rectangular tanks $(8.87 \times 2 \times 1.43 \mathrm{~m})$ with an operating level of $22,000 \mathrm{~L}$ each. Controlled conditions were established for temperature, salinity, dissolved oxygen, and $\mathrm{pH}$. Four $5 \mathrm{Hp}$ blowers (Baldor Reliance Industrial Motor) supplied aeration for the 20 tanks.

Three variables were analyzed in the production stage: survival (final production), number of larvae per gram, and a stress test (survival rate after stress). Survival was determined by estimating the number of postlarvae (P-12) at the end of the production cycle, based on the initial density of 3.76 million nauplii 5 stocked into each tank. The stress test to determine the survival and number of viable animals per gram consisted of transferring $100 \mathrm{P}-12$ from fresh water of 21 of salinity for $15 \mathrm{~min}$ and returning them to 21 of salinity for another $15 \mathrm{~min}$.

Five treatments with four replicates tanks were used, in which the supply of copepods and Artemia spp. offered throughout the cycle varied. The amount of these two feeds was modified from the standard amount regularly used by the company per cycle (Table 1). Nauplii at stage N5 was stocked per tank in 10,000 L of water, with $2,000 \mathrm{~L}$ of water with algae periodically added to reach 22,000 $\mathrm{L}$ in each tank. Two days after stocking, animal quality in each tank was assessed with a microscope to standardize the animals' quality by determining the percentage of deformed animals, which cannot exceed $20 \%$.

Daily water quality parameters (temperature, salinity, and dissolved oxygen) in the tanks were measured (Table 2) using a YSI Professional Series 2030 Pro meter. Also, algae counts were done every day. Treflan $^{\circledR}(0.5 \mathrm{~mL})$ was added in each tank to prevent fungal growth every $12 \mathrm{~h}$ from nauplii five to zoea three stages. Epicin ${ }^{\circledR} \mathrm{G} 2(5 \mathrm{~g})$ was added daily through two daily doses throughout the larval cycle. Additionally, 1,500 $\mathrm{g}$ of EDTA and 4,000 $\mathrm{g}$ of sodium bicarbonate were applied to the water reservoirs to control the presence of heavy metals and maintain alkalinity.

Diets in each treatment shared the same characteristics except for the amount of Artemia and copepods used. Diet with 0\% Artemia was supplemented with a higher quantity of liquid supplements to compensate for the absence of Artemia and copepods in mysis 1, 2, and 3. The number of copepods and Artemia used was based
Table 1. Amount of Artemia and copepods in larviculture diets used in LARVIPAC. Art: Artemia; Cop: copepods.

\begin{tabular}{lcc}
\hline \multirow{2}{*}{ Treatment } & \multicolumn{2}{c}{ Component $(\mathrm{g})$} \\
\cline { 2 - 3 } & Artemia & Copepod \\
\hline 100-0\% Art-Cop & 2,100 & 0 \\
75-25\% Art-Cop & 1,575 & 2,025 \\
50-50\% Art-Cop & 1,050 & 4,050 \\
25-75\% Art-Cop & 525 & 6,075 \\
0-100\% Art-Cop & 0 & 8,100 \\
\hline
\end{tabular}

Table 2. Optimal water quality parameters for larval development.

\begin{tabular}{lcc}
\hline Dissolved oxygen & Temperature & Salinity \\
\hline$\geq 3 \mathrm{~mL} \mathrm{~L}^{-1}$ & $31-32^{\circ} \mathrm{C}$ & $22-25$ \\
\hline
\end{tabular}

on the expected production of two million larvae from the 3,760,000 stocked. The number of copepods in the diet with $100 \%$ inclusion was estimated at $8.1 \mathrm{~kg}$ per tank per cycle; for the Artemia, the estimation at $100 \%$ inclusion was $2.1 \mathrm{~kg}$ per tank per cycle.

All diets were evaluated using a partial budget designed by the International Maize and Wheat Improvement Center (CIMMYT). Annual net benefits were determined, and marginal return rates on each diet were compared to the minimum acceptable rate set for farmers. The expected minimum return rate and residual analysis were determined to define which alternative among the five diets used is best for the producer (Harper et al., 2013). Annual net benefits (USD) for each treatment were calculated using Equation 1:

Annual net benefit $=$ annual gross benefit - annual costs that vary

Gross benefit was obtained by multiplying the average annual production of larvae of each treatment (larvae $\mathrm{m}^{-3} \mathrm{yr}^{-1}$ ), by its price in USD. Yearly production is estimated using the available number of cycles per year per treatment.

The selling price in Honduras, used to develop the partial budget, was USD 3,000 per million postlarvae (USD 3/thousand). Postlarvae quality is a determining factor in establishing the prestige factor of a laboratory to compensate for mortality. The marginal rate of return was obtained by dividing marginal annual net benefit by the increase in costs that vary due to the change of one diet to another (Eq. 2).

$$
\text { Marginal rate of return }=\frac{\Delta \text { annual net benefit }}{\Delta \text { annual costs that vary }} \times 100
$$

The farmer must establish a minimum acceptable rate for which he would be willing to change the current diet for a different one for shrimp larvae production, setting a minimum percentage between 50 and $100 \%$. 
According to CIMMYT, the marginal rate of return must be higher than the prescribed minimum acceptable rate of return, considered an alternative, along with a residual analysis to determine the optimal diet for the fish farmer.

Residual analysis indicates the difference in net benefit and the cost of additional investment (CIMMYT, 1998). This analysis supports conclusions with the marginal analysis. The residual is obtained by subtracting the product of the minimum rate of return and costs that vary from the net benefit (Eq. 3). Once the difference is obtained, the analysis continues comparing the residuals obtained in each treatment.

Residual $=$ annual net benefit $\mathrm{Ti}$ - (minimum acceptable rate $\times$ annual costs that vary $\mathrm{Ti}$ )

where, minimum acceptable rate: $100 \%$; Ti: treatment evaluated.

A completely randomized block design was used to group the experimental units into homogeneous groups (blocks). Each block included all treatments, and four repetitions were made simultaneously. An analysis of variance (ANOVA) was used to compare various groups in a quantitative variable with the "Statistical Analysis System" (SAS 9.4) program, and Duncan's multiple range test and LSMEANS $(P \leq 0.05)$ were used to detect statistical differences in means. The larvae obtained at harvest time were used to measure the following technical variables: 1) survival, 2) postlarvae per gram, 3) survival after a stress test.

After harvest, survival for all treatments showed no significant difference, which indicates that providing diets with reduced Artemia content, which has been the basis of larviculture shrimp feed, does not affect survival at the time of harvest, a possibility for cost reduction. Survival rates differ from the study by Amaya (1991), who concluded that postlarvae fed Artemia had a higher survival rate than fed copepods. Martín et al. (2006) determined that survival above $80 \%$ was possible with the use of zooplankton, specifically Moina micrura.

The average postlarvae per gram per treatment required to achieve the weight of one gram are shown in Table 3, and the stress test showed no differences between the treatments offered (Table 4). Results in this study differ from those of Martin et al. (2006), where complete Artemia replacement had a significant effect on growth. Artemia has a large energy reserve, highlighting its polyunsaturated fatty acids content (Villamar-Ochoa, 2000), although this could not cause differences in the size and weight of this food treated larvae.
Table 3. Survival of postlarvae (mean \pm standard deviation) in LARVIPAC.

\begin{tabular}{lcc}
\hline Treatment & $\begin{array}{c}\text { Harvest } \\
\text { survival }(\%)\end{array}$ & $\begin{array}{c}\text { Postlarvae } \\
\text { per gram }\end{array}$ \\
\hline Artemia $(100 \%)$ & 68 & $211 \pm 52.7$ \\
Artemia $(75 \%)$ & 61 & $271 \pm 37.5$ \\
Artemia $(50 \%)$ & 56 & $265 \pm 43.5$ \\
Artemia $(25 \%)$ & 59 & $250 \pm 53.5$ \\
Artemia $(0 \%)$ & 59 & $271 \pm 40.1$ \\
\hline$P$ & 0.34 & 0.34 \\
CV \% & 14.13 & 18.09 \\
\hline
\end{tabular}

Table 4. Stress test survival in LARVIPAC.

\begin{tabular}{lc}
\hline Treatment & Survival $(\%)$ \\
\hline Artemia $(100 \%)$ & 100 \\
Artemia $(75 \%)$ & 99.3 \\
Artemia $(50 \%)$ & 100 \\
Artemia $(25 \%)$ & 100 \\
Artemia $(0 \%)$ & 99.3 \\
\hline$P$ & 0.3 \\
CV \% & 4.62 \\
\hline
\end{tabular}

Table 5. Breakdown of production cycle gross benefit of Penaeus vannamei diets in LARVIPAC.

\begin{tabular}{lcc}
\hline Treatment & $\begin{array}{c}\text { Average yield } \\
\left(\mathrm{P} \mathrm{m}^{-3}\right)\end{array}$ & $\begin{array}{c}\text { Gross benefit } \\
(\mathrm{USD})\end{array}$ \\
\hline Artemia $(100 \%)$ & $2,356,500$ & 6,363 \\
Artemia $(75 \%)$ & $2,110,500$ & 5,698 \\
Artemia $(50 \%)$ & $1,975,750$ & 5,335 \\
Artemia $(25 \%)$ & $2,081,750$ & 5,621 \\
Artemia $(0 \%)$ & $2,055,250$ & 5549 \\
\hline
\end{tabular}

As per the stress test, Ogle et al. (1992) suggest that survival to different salinity changes is associated with age and time of exposure. Stress test results differ from the studies by Amaya (1991), Rees et al. (1994), and Sorgeloos et al. (2017), who concluded that larvae fed Artemia showed higher survival to this stress because of the energy reserves that it provided to the animal. The differences reported by Rees et al. (1994) and Sorgeloos et al. (2017) are probable because their experiments used Artemia with different polyunsaturated fatty acid enrichment while in this study the Artemia for all treatments used was the same. However, the stress data are consistent with the study by Martin et al. (2006), where P-9 shrimp fed Artemia did not outperform that fed zooplankton.

The partial budget used the annual gross benefit generated by the sale of the average production of larvae of each treatment, represented as live larvae at the end of the production cycle (Table 5). The live lar- 
vae are sold at a retail price of USD 3/thousand adjusted to the standard rate (10\%) of additional larvae that the laboratory provides to the buyer. The estimated number of production cycles for each treatment was approximately 12 . Treatments differed on costs that vary due to the singular percentages of Artemia and copepods used in each. The costs that vary per cycle, in descending order of percentage of Artemia $(100,75,50$, 25 , and 0 ) and increasing percentage of copepods, are approximately $177,159,141,122$, and 111 USD per 22 $\mathrm{m}^{3}$. The annual costs that vary, in descending order of percentage of Artemia $(100,75,50,25,0)$ and increasing percentage of copepods, with the aforementioned costs per cycle and the 12 cycles per year, amount to 2,$158 ; 1,935 ; 1,712 ; 1,489$; and 1,351 USD per $22 \mathrm{~m}^{3}$, respectively. The data in the following tables may vary due to rounding. The annual net benefit, the difference between the annual gross benefit and the annual costs that vary, is higher using only Artemia compared to the other treatments, although with higher costs that vary (Table 6).
The marginal rate of return is part of the economic analysis and shows how many dollars would be obtained in return by switching from one diet to another for every additional dollar invested. Data obtained from the experiment determined that the treatment with $100 \%$ Artemia had the highest marginal rate of return, followed by treatment 75:25\% Artemia: copepods and treatment 25:75\% Artemia:copepods. Treatment 50:50\% Artemia:copepods is dominated since it has the lowest net benefits and higher costs that vary and lower net benefits, as shown in Figure 1. The minimum rate of return used was $100 \%$ on the investment. This rate was taken considering the cost of capital and risk of using alternatives to Artemia, this being the current paradigm of the shrimp industry. A graph is presented indicating the relationship of annual net benefits and annual costs that vary (Fig. 1) to establish dominance among treatments. According to this experiment, the farmer would get the highest return on his investment with 100\% Artemia compared to other treatments for its expected higher net benefit compared to the low additional cost incurred compared to other diets.

Table 6. Annual net benefits (USD/22 $\mathrm{m}^{3}$ ) for Penaeus vannamei in LARVIPAC.

\begin{tabular}{lccc}
\hline Treatment & $\begin{array}{c}\text { Annual gross } \\
\text { benefit }\end{array}$ & $\begin{array}{c}\text { Annual costs } \\
\text { that vary }\end{array}$ & $\begin{array}{c}\text { Annual net } \\
\text { benefits }\end{array}$ \\
\hline Artemia $(100 \%)$ & 77,411 & 2,158 & 75,253 \\
Artemia $(75 \%)$ & 69,330 & 1,935 & 67,395 \\
Artemia $(50 \%)$ & 64,903 & 1,712 & 63,191 \\
Artemia $(25 \%)$ & 68,385 & 1,489 & 66,896 \\
Artemia $(0 \%)$ & 67,515 & 1,351 & 66,164 \\
\hline
\end{tabular}

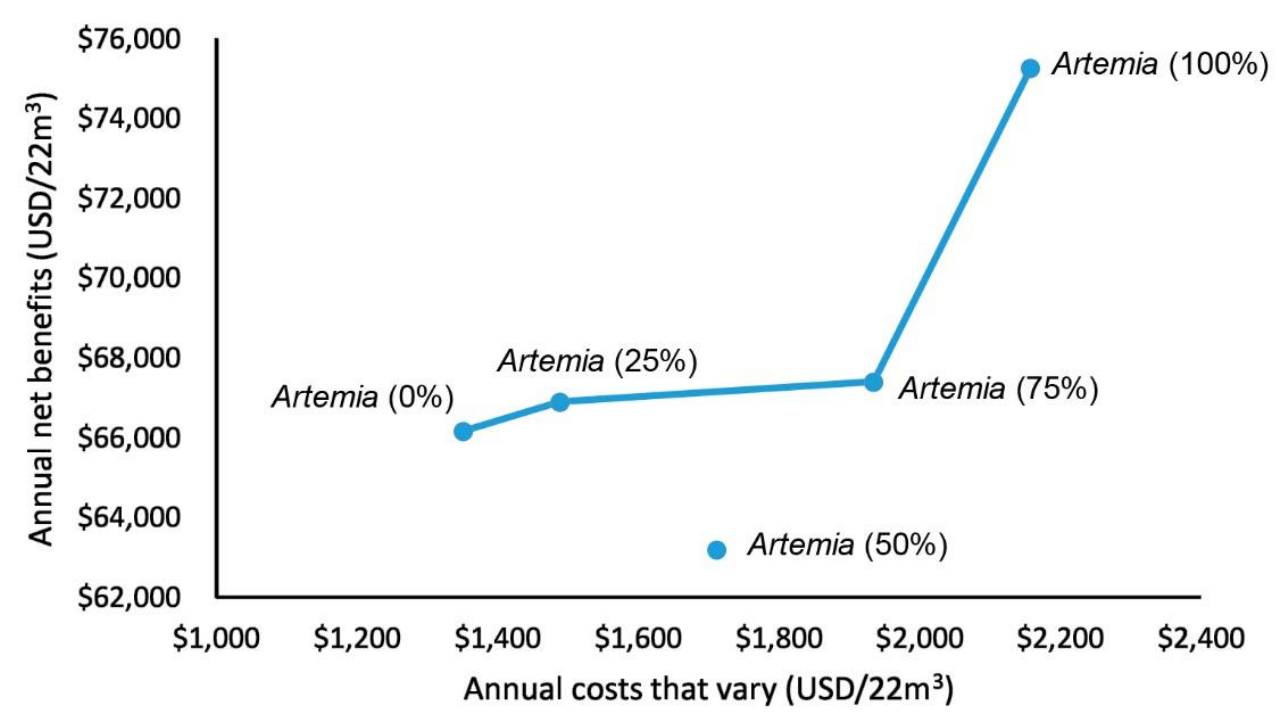

Figure 1. Annual net benefits and annual costs vary for different diets for Penaeus vannamei shrimp larvae (USD/22 $\mathrm{m}^{3}$ ), LARVIPAC. 


\section{REFERENCES}

Amaya, N. 1991. Alimentación de post-larvas de camarón con copépodos cosechados en piscinas Tesis, Escuela Superior Politécnica del Litoral, Guayaquil, 74 pp.

Brett, M.T. \& Müller-Navarra, D.C. 1997. The role of highly unsaturated fatty acids in aquatic foodweb processes. Freshwater Biology, 38(3): 483-499.

Centro Internacional de Mejoramiento de Maíz y Trigo (CIMMYT). 1998. La formulación de recomendaciones a partir de datos agrónomicos: un manual metodológico de evaluación económica. CIMMYT, Texcoco.

Harper, J.K., Cornelisse, S. \& Kimé, L.F.J. 2013. Agricultural hyde alternatives: budgeting for agricultural decision making. Penn State Extension, Pennsylvania, 8 pp.

D'Abramo, L.R. \& Sheen, S.S. 1993. Polyunsaturated fatty acid nutrition in juvenile freshwater prawn Macrobrachium rosenbergii. Aquaculture, 115: 63-86.

Marroquín, E.L., Valdés, M.A. \& Gonsalez, J.E. 2012. Potencial del camarón marino (Litopenaeus vannamei) para cultivo en agua dulce. Tesis, Universidad de San Carlos de Guatemala, Ciudad de Guatemala, 78 pp.

Martin, L., Arenal, A., Fajardo, J., Pimentel, E., Hidalgo, L., Pacheco, M. \& Santiesteban, D. 2006. Complete and partial replacement of Artemia nauplii by Moina micrura during the early postlarval culture of white shrimp (Litopenaeus schmitti). Aquaculture Nutrition, 12: 89-96.

Martinez-Córdova, L.R., Martínez-Porchas, M., LopezElías, J.A., Campaña-Torres, A., Miranda-Baeza, A., Ballester, E. \& Porchas-Cornejo, A. 2010. Alimento natural en acuacultura: una revisión actualizada. In: Cruz-Suarez, L.E., Ricque-Marie, D., Tapia- Salazar, M., Nieto-López, M.G., Cavazos-Villareal, D.A. \& Gamboa-Delgado, J. (Eds.). Avances en Nutrición Acuícola X. Memorias del X Simposio Internacional de Nutrición Acuícola, Universidad Autónoma de Nuevo León, Monterrey, pp. 668-699.

Received: 11 November 2019; Accepted: 29 May 2020
Ogle, J.T., Beaugez, K. \& Lotz, J.M. 1992. Effects of salinity on survival and growth of postlarval Penaeus vannamei. Gulf Research Reports, 8(4): 415-421.

Puello, A.C., González-Rodríguez, B. \& García-Ortega, A. 2008. Investigación en producción y uso de copépodos en larvicultura marina. Centro de Investigación en Alimentación y Desarrollo, Unidad de Acuicultura y Manejo Ambiental, Mazatlán, 18 pp.

Rees, J.F., Curé, K., Piyatiratitivorakul, S., Menasveta, P. \& Sorgeloos, P. 1994. Osmotic stress resistance as a quality diagnostic for penaeid postlarvae. In: Chou, L.M., Munro, A.D., Lam, T.J., Chen, T.W., Cheong, I.K.K., Ding, K.K., et al. (Eds.). The third Asian fsheries forum. Asian Fisheries Society, Manila, pp. 1025-1028.

Sanchez, A.A. 2001. Project design and implementation of a system of extraction/harvesting, storage, preservation, transportation, and marketing of fishery products and other highly perishable in the communities in the Meta River. IICA Inter-American Institute for Cooperation on Agriculture, Consultancies No. 566, 16 pp.

Sorgeloos, P., Coutteau, P., Dhert, P., Merchie, G. \& Lavens, P. 2017. Use of brine shrimp, Artemia spp. in larval crustacean nutrition: a review. Reviews in Fisheries Science, 6(1-2): 55-68.

Stoner, A.W. \& Zimmerman, R.J. 1988. Food pathways associated with penaeid shrimps in a mangrovefringed estuary. Fishery Bulletin, 86(8): 543-551.

Støttrup, J.G. \& Norsker, N.H. 1997. Production and use of copepods in marine fish larviculture. Aquaculture, 155: 231-247.

Tahim, E.F., Dumaceno, M.N. \& De Araujo Jr., I.F. 2014. Trayectoria tecnológica e innovación en la industria del cultivo de camarón en el nordeste de Brasil. Revista Galega de Economía, 23(3): 9-32.

Villamar-Ochoa, C.A. 2000. La Artemia salina y su importancia en la producción camaronera. AquaTIC, 11: 84-91. 